\title{
CORPORATE GOVERNANCE DAN PENGUNGKAPAN ENTERPRISE RISK MANAGEMENT (ERM): STUDI EMPIRIS PERUSAHAAN NON KEUANGAN INDONESIA.
}

\author{
Hudi Kurniawanto \\ Fakultas Ekonomi, Universitas Slamet Riyadi Surakarta, Indonesia \\ hudi.kurniawanto@gmail.com \\ Bambang Widarno \\ Fakultas Ekonomi, Universitas Slamet Riyadi Surakarta, Indonesia \\ bwidarno@yahoo.com
}

\begin{abstract}
The purpose of this study is to examine the effect of corporate governance on enterprise risk management disclosure in Indonesia. Corporate governance is defined as size of the board of commissioners and the proportion of independent commissioners. This study also uses firm size as a control variable.

The samples are selected using purposive sampling, with 117 annual reports from non-financial companies listed in Indonesia Stock Exchange in the year 2014-2016. The results of this study prove that size of the board of commissioners has effects on enterprise risk management disclosure, while the proportion of independent commissioners does not affect enterprise risk management disclosure. Variable company size in this study affect enterprise risk management disclosure. This shows that the greater the number of commissioners, the better the level of supervision and pressure on management, thus encouraging management to be more transparent in disclosing enterprise risk management.
\end{abstract}

Keywords: Enterprise risk management disclosure, Corporate Governance, Nonfinancial company listed on the Indonesia Stock Exchange.

\section{PENDAHULUAN}

Penelitian ini bertujuan untuk menguji pengaruh corporate governance dan pengungkapan enterprise risk managemen (ERM) pada perusahaan non keuangan Indonesia. Corporate governance dalam penelitian ini direpresentasikan oleh ukuran dewan komisaris, dan proporsi komisaris independen.

Praktik corporate governance Indonesia berdasarkan laporan The Word Bank, dalam Reports on the Observance of Standards and Codes (ROSC), menyebutkan skor corporate governance negara Indonesia 68 point (59\%) lebih rendah dibanding skor corporate governance negara Malaysia 88 point $(76 \%)$. Perbedaan ini disebabkan terutama oleh kelemahan item pengungkapan dan transparansi dimana skor Indonesia 12 point dan skor Malaysia 17 point (McGee, 2009).

Berdasarkan ROSC pengungkapan risiko di Indonesia rendah. Problem rendahnya pengungkapan risiko penting untuk diteliti karena para pengguna laporan tahunan membutuhkan informasi lebih lanjut untuk diungkapkan terutama berkaitan dengan 
sistem manajemen risiko. Dobler (2005) menyatakan bahwa pengungkapan risiko perusahaan sangat penting untuk menginformasikan kepada pengguna tentang dampak risiko terhadap posisi keuangan masa depan perusahaan.

Perubahan dalam lingkungan bisnis saat ini membuat perusahaanperusahaan lebih mengandalkan pada instrumen keuangan dan transaksitransaksi internasional yang meningkatkan pentingnya pengungkapan risiko perusahaan, terutama pada perusahaan-perusahaan nonkeuangan (Dobler, 2008). Perusahaan-perusahaan berusaha untuk memenuhi kebutuhan pengguna informasi akuntansi dengan mengungkapkan informasi secara lebih mengenai risiko-risiko yang berbeda yang dihadapi dan kelangsungan operasionalnya. Informasi tersebut membantu pengguna untuk menilai risiko masa kini dan masa depan, yang penting untuk mengoptimalkan pendapatan mereka (Abraham dan Cox, 2007).

Solomon, Norton, dan Josef (2000) menunjukkan permintaan yang kuat terhadap peningkatkan pengungkapan risiko dari investor institusional untuk meningkatkan keputusan investasi. Pengungkapan risiko membantu investor dalam proses pengambilan keputusan investasi dengan mengevaluasi informasi yang diungkapkan oleh perusahaan dalam rangka membangun tingkatan-tingkatan risiko yang dihadapinya, maka keputusan mereka akan diambil berdasarkan pertimbangan pengembalian dan risiko yang diharapkan (Cabedo dan Tirado, 2004).

Pengungkapan risiko akan mendorong pada manajemen risiko yang lebih baik, serta peningkatan akuntabilitas pengelolaan, perlindungan investor, dan kegunaan pelaporan keuangan (Institute of Chartered Accountants in England and Wales ICAEW, 1997). Hal ini akan membantu pengguna laporan keuangan untuk mengidentifikasi potensi masalah (atau peluang) manajerial dan menilai efektivitas manajemen dalam menangani masalah ini (Lajili dan Zéghal, 2005). Di sisi lain, perusahaan juga mendapat manfaat dari pengungkapan risiko dengan mengurangi kemungkinan kegagalan keuangan (Beretta dan Bozzolan, 2004), juga dapat membuat penurunan biaya keuangan eksternal (Linsley dan Shrives, 2006).

Pengungkapan risiko merupakan salah satu bentuk dalam penerapan mekanisme corporate governance. Corporate governance adalah seperangkat hubungan diantara manajemen, direksi, dewan komisaris, investor dan stakeholders yang mengatur dan mengarahkan kegiatan perusahaan (Choi dan Meek, 2011). Pengungkapan risiko mendorong terwujudnya good corporate governance yang diperlukan untuk menjaga kelangsungan hidup perusahaan. Good corporate 
governance dilakukan melalui pengelolaan yang didasarkan pada asas transparansi, akuntabilitas, responsibilitas, independensi serta kewajaran dan kesetaraan (Choi dan Meek, 2011).

Beberapa hal yang yang terkait dengan mekanisme corporate governance adalah peran dewan komisaris (jumlah dewan komisaris serta independensi dewan komisaris). Dechow et al., (1996) dan Beasley (1996) menemukan pengaruh yang signifikan antara peran dewan komisaris dengan pelaporan keuangan. Mereka menemukan bahwa ukuran dan independensi dewan komisaris mempengaruhi kemampuan mereka dalam memonitor proses pelaporan keuangan.

Penelitian terdahulu tentang pengungkapan risiko dikaitkan dengan corporate covernance seperti ukuran dewan komisaris dan proporsi komisaris independen hasilnya tidak konsisten. Penelitian Singh et al. (2004) menemukan bahwa jumlah dewan komisaris berpengaruh positif terhadap pengungkapan risiko perusahaan, sedangkan Meizaroh dan Lucianda (2011) menemukan tidak ada pengaruh antara kedua variabel. Penelitian Ho dan Wang (2001), Haniffa dan Cooke (2002), Vandemele et al. (2009) menemukan tidak ada pengaruh antara proporsi komisaris komisaris independen dan pengungkapan risiko perusahaan, sedangkan penelitian Forker (1992), Cheng dan Courtenay
(2006) menemukan pengaruh antara kedua variabel.

Di Indonesia, penelitian yang membahas mengernai ERM belum banyak dilakukan, walaupun perkembangan ERM mulai meningkat. Oleh karena itu, penelitian mengenai ERM sangat menarik untuk dilakukan mengingat ERM merupakan isu yang masih baru, juga ERM erat hubungannya dengan dengan implementasi good corporate governance, karena aspek pengawasan yang dilakukan dewan komisaris merupakan kunci penting terlaksananya sistem manajemen risiko yang efektif.

Berdasarkan latar belakang diatas, penelitian ini bertujuan untuk menguji apakah corporate governance dapat mempengaruhi pengungkapan enterprise risk management. Pertanyaan utama penelitian ini adalah apakah ukuran dewan komisaris, dan proporsi komisaris independen mempengaruhi pengungkapan enterprise risk management.

\section{TINJAUAN PUSTAKA DAN PENGEMBANGAN HIPOTESIS}

\subsection{Teori Keagenan}

Jensen dan Meckling (1976) menyatakan bahwa pemisahan kepemilikan dan pengendalian perusahaan akan menimbulkan masalah keagenan karena adanya perbedaan kepentingan antara pemilik perusahaan sebagai prinsipal dengan pihak manajemen sebagai agen. Masalah keagenan juga merupakan elemen pokok dari pandangan kontraktual suatu 
perusahaan (Jensen dan Meckling, 1976; Fama dan Jensen, 1983).

Menurut Morris (1987) teori keagenan berfokus pada masalah kepentingan antara prinsipal (pemasok modal) dan agen (manajemen). Masalah tersebut antara lain, dalam pembagian kepemilikan dan pengendalian dalam perusahaan, antara pemasok modal, dan pembagian risiko, serta pengambilan keputusan dan fungsi pengendalian dalam perusahaan.

Teori keagenan menunjukkan bahwa timbulnya suatu masalah kepentingan menyebabkan munculnya biaya keagenan (agency cost) yang memerlukan dorongan untuk menguranginya. Menurut Morris (1987), timbulnya biaya keagenan pertama karena adanya penurunan nilai perusahaan pada saat pemegang saham menganggap bahwa manajer tidak memperhatikan kepentingannya karena manajer tidak bertindak efisien atau tidak memilih proyek yang menguntungkan seperti yang diinginkan oleh pemegang saham. Kedua, diperlukannya biaya pengawasan dan biaya untuk mengikat (monitoring and bonding cost) supaya manajer bertindak sesuai kepentingan pemegang saham.

Perspektif teori keagenan tersebut merupakan dasar yang digunakan untuk memahami praktik pengungkapan risiko. Manajer sebagai pengelola perusahaan tentu akan mengetahui lebih banyak informasi internal dan prospek perusahaan di masa yang akan datang daripada pemilik. Hal tersebut menyebabkan terjadinya asimetri informasi diantara keduanya, khususnya yang akan merugikan pemilik. Pemilik dalam hal ini adalah pemegang saham dan kreditur. Oleh karena itu, untuk mengurangi masalah keagenan tersebut, manajer harus menyajikan informasi yang relevan untuk membuktikan tindakan-tindakan mereka demi kepentingan pemegang saham dan kreditur.

Teori keagenan dalam praktik pengungkapan risiko dapat menjelaskan bagaimana manajer memberikan informasi mengenai risiko kepada pemegang saham dan kreditur dengan menyediakan informasi yang reliabel. Manajer dalam hal ini merupakan pihak internal perusahaan yang memiliki informasi mengenai risiko sedangkan pemegang saham dan kreditur sebagai pihak eksternal perusahaan yang biasanya tidak memiliki informasi mengenai risiko. Ketersediaan informasi yang reliabel mengenai risiko oleh manajer kepada pemegang saham dan kreditur akan mengurangi masalah asimetri informasi (Elzahar dan Hussainey, 2012).

\begin{tabular}{lcr}
\multicolumn{1}{c}{ Teori } & keagenan & dalam \\
pengaruhnya & dengan & praktik \\
pengungkapan risiko adalah dapat & danin \\
menjelaskan bagaimana pemilik yakin \\
bahwa manajer mengungkapkan \\
informasi yang relevan dan reliabel \\
mengenai risiko yang dihadapi
\end{tabular}


perusahaan. Selain itu, pemasok modal meyakini bahwa manajer tidak mengurangi informasi mengenai risiko agar pemasok modal tetap menginvestasikan modalnya. Dengan kata lain, praktik pengungkapan risiko perusahaan diharapkan dapat berfungsi untuk menekan atau menurunkan biaya keagenan.

\subsection{Corporate Governance (CG)}

Corporate governance adalah seperangkat hubungan diantara manajemen, direksi, dewan komisaris, investor dan stakeholders yang mengatur dan mengarahkan kegiatan perusahaan (Choi dan Meek, 2011). Pengungkapan risiko mendorong terwujudnya good corporate governance yang diperlukan untuk menjaga kelangsungan hidup perusahaan. Good corporate governance dilakukan melalui pengelolaan yang didasarkan pada asas transparansi, akuntabilitas, responsibilitas, independensi serta kewajaran dan kesetaraan (Choi dan Meek, 2011).

Monks dan Minnow mendefinisikan $\mathrm{CG}$ sebagai hubungan berbagai partisipan dalam menentukan arah dan kinerja korporasi. Definisi lain diajukan oleh Shleifer dan Vishny (1997) yang menyebutkan bahwa CG sebagai bagian dari cara atau mekanisme untuk meyakinkan para pemilik modal dalam memperoleh imbal hasil yang sesuai dengan investasi yang ditanamkan.
Berdasarkan definisi-definisi tersebut dapat disimpulkan bahwa CG merupakan sistem yang dilakukan oleh semua pihak yang berkepentingan dengan perusahaan untuk menjalankan usahanya secara baik sesuai dengan hak dan kewajiban masing- masing dalam rangka untuk meningkatkan kesejahteraan semua pihak. Sebagai suatu sistem, mekanisme CG memerlukan berbagai perangkat, yaitu: company law, securities law, listing rules, accounting standards, bankcruptcy and insolvency laws, competition or anti-trust laws, important of court (judicial redress), market institutions and practices, codes of good governance (best practices), dan mechanisme for addressing investors/minority shareholder expectation (Lukviarman, 2004).

\subsection{Pengungkapan Enterprise Risk Management (ERM)}

\subsubsection{Risiko dan Manajemen Risiko}

Risiko didefinisikan sebagai suatu keadaan yang dapat menghambat organisasi dalam mencapai tujuan yang telah ditetapkan (Tunggal, 2009). Risiko merupakan perubahan dari kerugian, kerusakan atau kehilangan yang membahayakan (Chorafas, 1990)

Manajemen risiko menurut Amran et al. (2009) adalah metode dan proses yang digunakan oleh perusahaan untuk mengelola risiko (atau menangkap peluang) yang berpengaruh dengan pencapaian tujuan-tujuan perusahaan. Selanjutnya, 
Lajili dan Zeghal (2005) memberikan suatu kerangka manajemen risiko yang melibatkan proses-proses sebagai berikut: 1) mengidentifikasi secara hati-hati, mengukur, dan menilai tipe risiko dan kontinjensi risiko yang mungkin dihadapi oleh perusahaan, 2) memformulasikan model reaksi atau tindakan strategis yang tepat untuk menghadapi risiko tersebut, termasuk menentukan kapasitas dalam menerima risiko yaitu dengan mengurangi risiko atau memindahkan risiko tersebut ke pihak lain.

Tujuan utama dari Risk Management adalah untuk memonitor kinerja dari tindakan yang merespon risiko untuk memberikan informasi yang dibutuhkan sebagai tindakan intervensi manajemen risiko yang pro aktif. Ada lima elemen penting dalam konsep tersebut yaitu Corporate Governance, Internal Control, Implementation, Risk Management Process dan Sources of Risk.

\subsubsection{Definisi Enterprise Risk} Management (ERM)

Committee of Sponsoring Organization of The Treadway Commission (COSO) dalam executive summary yang dikeluarkan pada bulan September 2004 menyatakan bahwa ERM meliputi:

1) Aligning risk appetite and strategy (Menyelaraskan batas risiko dan strategi risiko). Manajemen mempertimbangkan batas risiko dari entitas dalam mengevaluasi alternatif strategi, menetapkan tujuan yang berhubungan dengan hal itu, dan mengembangkan mekanisme untuk mengelola risiko yang berhubungan yang ditimbulkannya.

2) Enhancing risk response decisions (Meningkatkan keputusan tanggapan risiko). ERM menyediakan kekuatan untuk mendifinisikan dan menyeleksi antara alternatif respon dari risiko: menghindari, mengurangi, membagi, dan menerima risiko.

3) Reducing operational surprise and losses (Mengurangi kejutan dan kerugian operasional). Entitas mengambil keuntungan dari meningkatkan kemampuan untuk mengidentifikasi peristiwa yang berpotensi dan respon yang ada, mengurangi adanya kejutan-kejutan dan menghubungkannya dengan biaya atau kerugian.

4) Identifying and managing multiple and cross-enterprise risk (Mengidentifikasi dan mengelola beberapa dan lintasrisiko perusahaan). Setiap perusahaan menghadapi berbagai risiko yang mempengaruhi berbagai bagian organisasi, dan manajemen risiko perusahaan memfasilitasi respon yang efektif kepada semua bagian yang terkena 
dampaknya dan menggabungkan respon-respon tersebut kepada bermacam-macam risiko.

5) Seizing opportunities (peluang perebutan).

Dengan mempertimbangkan hal terbesar dari potensi kejadian, manajemen dalam hal ini berada pada posisi untuk mengidentifikasi dan melakukan tindakan proaktif untuk menyadari kesempatan yang ada.

6) Improving deployment of capital (Meningkatkan penyebaran modal). Penyediaan informasi risiko yang baik membuat manajemen dapat menilai secara efektif keseluruhan modal yang dibutuhkan dan meningkatkan pengalokasian modal.

ERM dapat dijelaskan sebagai
suatu proses untuk membuka,
mengidentifikasi dan mengevaluasi
risiko-risiko tersebut, baik risiko
individual maupun konteks yang lebih
luas atas risiko-risiko berbeda yang
saling berhubungan yang
mempengaruhi perusahaan (Tunggal,
2009). Sementara COSO (2004)
menyatakan: Enterprise Risk Management adalah sebuah proses yang melibatkan keseluruhan keseluruhan entitas mulai dari dewan direksi, manajemen dan pejabat lainnya, yang diaplikasikan ke dalam penyusunan strategi dan melingkupi keseluruhan perusahaan, yang didesain untuk mengidentifikasi kejadian yang berpotensi yang dapat berakibat pada entitas, dan mengelola risiko pada tingkat risiko yang dikehendaki untuk menyediakan penjaminan yang wajar dalam rangka mencapai tujuan dari entitas.

Konsep dasar ERM dapat diterjemahkan sebagai berikut:

1) Sebuah proses yang berjalan dan mengalir melalui entitas

2) Dipengaruhi oleh manusia di setiap tingkatan organisasi

3) Dijalankan pada saat penetapan strategi

4) Berlaku ke seluruh perusahaan, pada tiap tingkatan dan unit, termasuk menetapkan cara pandang risiko pada sebuah portopolio pada tingkatan entitas

5) Dirancang untuk mengidentifikasi peristiwa yang berpotensi mempunyai dampak terhadap entitas dan mengelola risiko dalam batas jangkauan risiko itu sendiri.

6) Dapat memberikan jaminan yang masuk akal kepada entitas dan dewan perusahaan

7) Mendorong untuk mencapai satu atau lebih tujuan yang berbeda tetapi terkait satu sama lain.

Dengan kata lain ERM adalah sebuah proses yang dipengaruhi oleh dewan perusahaan, manajemen, personil lain entitas tersebut, diterapkan dalam penetapan strategi dan berlaku di seluruh perusahaan, dirancang untuk 
mengenali peristiwa potensial yang dapat mempengaruhi entitas itu, dan mengelola risiko agar tetap ada dalam jangkauan risikonya, sehingga dapat memberikan jaminan yang wajar mengenai, pencapaian tujuan entitas (Tunggal, 2009).

\subsubsection{Tujuan dan Komponen}

Enterprise Risk Management (ERM)

COSO ERM Framework (2004) membagi

tujuan

(objectives)

manajemen risiko perusahaan ke dalam empat kategori besar:

1) Strategic - tujuan yang ditetapkan pada tingkat manajemen atas, disatukan dan dibuat untuk mendukung misi dari perusahaan.

2) Operations - penggunaan sumber daya secara efektif dan efisien

3) Reporting - pelaporan yang dapat dipercaya

4) Compliance - patuh pada hukum dan peraturan yang berlaku

Menurut COSO ERM framework, terdapat delapan komponen ERM yang harus ada dan berjalan agar dapat dikatakan ERM efektif:

1) Internal Enviroment

Komponen ini mencerminkan selera perusahaan terhadap risiko yang dapat memberikan gambaran risiko dan pengendalian yang harus disadari/diketahui oleh seluruh jajaran dalam perusahaan. Manajemen bertanggung jawab dalam menetapkan sikap terhadap risiko kepada seluruh jajaran dalam perusahaan sebagai guidelines

2) Objective Setting

Perusahaan perlu menetapkan tujuan-tujuan strategis secara luas dan risiko yang dapat diterima. Strategic objectives mencerminkan pilihan manajemen mengenai bagaimana perusahaan, khususnya bagi pemegang saham. Selanjutnya, perusahaan harus menetapkan juga risiko yang berkaitan dengan objectivesnya.

3) Event Identification

Manajemen harus mempunyai proses yang dilakukan untuk mengidentifikasi kejadian yang mempunyai pengaruh positif maupun negatif bagi strategi risiko yang berhubungan. Berdasarkan risiko yang dapat ditoleransi, perusahaan dapat mempertimbangkan kejadian internal atau eksternal yang dapat menjadi risiko baru atau mengurangi area risiko yang ada.

4) Risk Assessment

Pada saat terdapat suatu kejadian yang merupakan suatu risiko, manajemen perlu mempertimbangkan bagaimana dampak yang dapat ditimbulkan dari kejadian tersebut terhadap ERM objectives perusahaan, dilihat dari frekuensi dan 
seberapa besar pengaruh

kejadian tersebut.

5) Risk Response

Manajemen harus menetapkan berbagai pilihan tanggapan (response) terhadap risiko dan mempertimbangkan

konsekuensinya pada sering dan besarnya pengaruh dari kejadian tersebut, berkaitan dengan toleransi risiko perusahaan. Tanggapan terhadap risiko: menghindari, mengurangi, membagi, atau menerima. Penelaahan terhadap tanggapan atas risiko dan jaminan keyakinan bahwa beberapa risk responses diambil dan diimplementasikan merupakan suatu komponen kunci dari suatu ERM framework perusahaan.

6) Control Activities

Kebijakan dan prosedur harus ada untuk meyakinkan bahwa tanggapan terhadap risiko yang memadai sudah dilakukan. Control activities ini harus ada pada setiap level dan fungsi dalam perusahaan, termasuk approval, authorization, performance review, safety and security issue, dan segregation of duties yang memadai

7) Information and Communication Informasi atas risiko yang berkaitan dengan perusahaan baik yang berasal dari pihak luar ataupun pihak internal harus diidentifikasi, diolah, dan dikomunikasikan kepada pihakpihak yang mempunyai kaitan dan tanggung jawab. Komunikasi yang efektif harus mengalir ke seluruh level perusahaan dan juga ke pihakpihak eksternal seperti pelanggan, pemasok, pemerintah maupun pemegang saham.

8) Monitoring

Risk monitoring merupakan prosedur yang terus menerus harus dilakukan untuk mengawasi program ERM dan kualitasnya dari waktu ke waktu.

\subsection{Pengembangan Hipotesis}

Dewan komisaris adalah suatu bagian yang penting dalam mekanisme corporate governance dan merupakan pusat internal corporate governance (Lukviarman, 2007). Salah satu fungsi dewan komisaris dalam National Code for Good Corporate Governance (2001) adalah memastikan bahwa perusahaan telah melakukan tanggungjawab sosial dan mempertimbangkan kepentingan berbagai stakeholder perusahaan.

Menurut Dalton et al. (1999) ukuran dewan komisaris yang optimum lebih efektif daripada ukuran dewan komisaris yang kecil. Berdasarkan penelitian yang dilakukan Abeysekera (2008) jumlah dewan yang dinilai efektif berada pada rentang lebih dari lima orang dan kurang dari empat belas orang. Jumlah dewan yang besar dapat mempengaruhi keputusan pengungkapan sukarela dan luas 
(Elzahar dan Hussainey, 2012). Jumlah Dewan Komisaris berpengaruh positif terhadap pengungkapan risiko perusahaan (Singh et al., 2004). Berdasarkan uraian diatas hipotesis yang dapat dikembangkan adalah

$$
\begin{aligned}
\mathrm{H}_{1} \text { : Ukuran Dewan Komisaris } \\
\text { berpengaruh positif terhadap } \\
\text { pengungkapan Enterprise Risk } \\
\text { Management dalam laporan } \\
\text { tahunan. }
\end{aligned}
$$

Proporsi komisaris independen adalah susunan anggota dewan komisaris dalam suatu perusahaan yang dipilih oleh pihak dari luar dan dalam perusahaan. Menurut teori keagenan, fungsi pengawasan dewan komisaris adalah untuk meyakinkan manajemen perusahaan memenuhi kepentingan pemegang saham. Komisaris independen diharapkan dapat memberikan saran yang independen kepada anggota komisaris yang ditunjuk oleh perusahaan. Dewan komisaris dengan proporsi anggota komisaris independen yang lebih besar diharapkan dapat lebih efektif dalam melaksanakan fungsi pengawasannya. Hal ini dapat mempengaruhi secara positif terhadap kualitas pelaporan akuntansi dan bertujuan untuk memberikan sinyal baik mengenai kompetensi mereka kepada potential employers (Fama dan Jensen 1983).

Penelitian terdahulu tentang pengaruh antara Proporsi komisaris independen dan pengungkapan beragam. Beberapa penelitian menemukan pengaruh yang tidak signifikan antara kedua variabel (Ho dan Wong, 2001;. Haniffa dan Cooke, 2002, dan Vandemele et al., 2009), sementara yang lain menemukan hubungan positif (Forker, 1992; Cheng dan Courtenay 2006, Abraham dan Cox, 2007). Berdasarkan uraian di atas, maka dapat dikembangkan hipotesis:

$\mathrm{H}_{2}$ : Proporsi komisaris independen berpengaruh positif terhadap pengungkapan Enterprise Risk Management dalam laporan tahunan.

\section{METODE PENELITIAN}

\subsection{Populasi, Sampel, dan Teknik Pengambilan Sampel}

Populasi penelitian ini adalah perusahaan non keuangan yang terdaftar di Bursa Efek Indonesia tahun 20142016. Sampel dipilih dengan menggunakan purposive sampling dengan kriteria: 1) Perusahaan non keuangan yang terdaftar di Bursa Efek Indonesia tahun 2014-2016. 2) Perusahaan yang mempublikasikan laporan keuangan dan annual report selama tahun 2014-2016. 3) Perusahaan yang memiliki kelengkapan data mengenai ukuran dewan komisaris dan komisaris independen. Berdasarkan kriteria tersebut, diperoleh jumlah sampel sebanyak 117 annual report yang memenuhi kriteria.

\subsection{Data dan Metode Pengumpulan}

\section{Data.}

Metode pengumpulan data pada penelitian ini menggunakan data sekunder yang diambil dari laporan tahunan perusahaan non keuangan yang terdaftar di Bursa Efek Indonesia pada tahun 2014-2016. Data sekunder yang 
dikumpulkan diperoleh dari situs www.idx.co.id, dan dari situs masingmasing perusahaan sampel. Kerangka mengenai hubungan antar masingmasing variabel dapat dilihat pada gambar dibawah ini:

Gambar 3.1 Skema Konseptual Penelitian

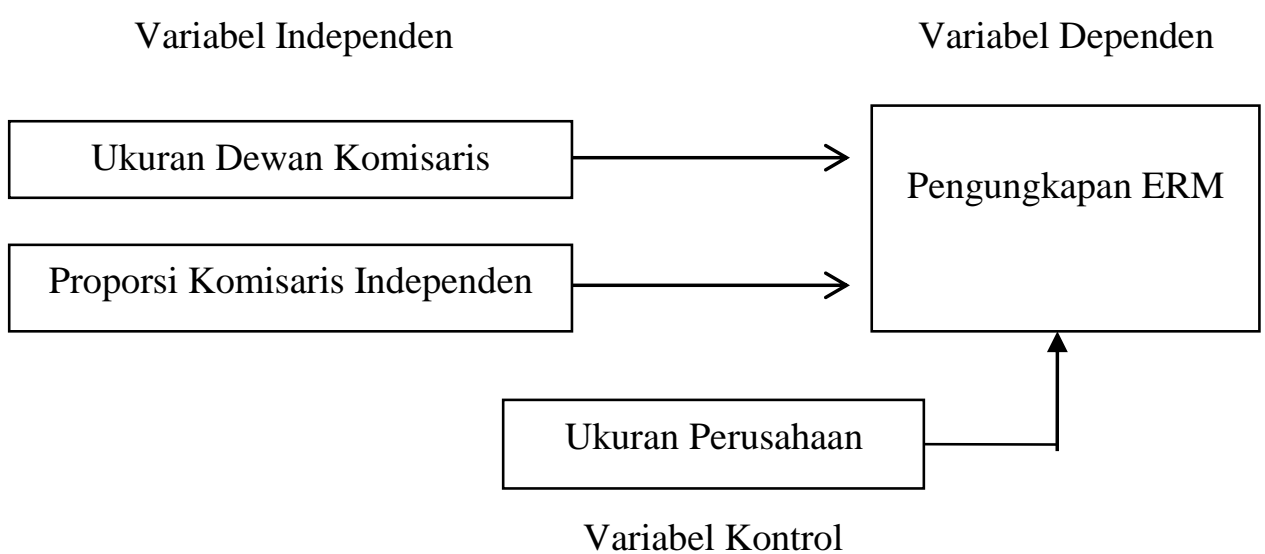

Sumber: Dikembangkan Oleh Peneliti

$\begin{array}{llllr}\text { 3.3 Definisi Operasional dan } & \text { dependen adalah ukuran dewan } \\ \text { Pengukuran Variabel } & & \text { komisaris dan proporsi komisaris } \\ \text { Variabel depende dalam penelitian ini } & \text { independen serta variabel kontrol adalah } \\ \text { adalah pengungkapan Enterprise Risk } & \text { ukuran } & \text { perusahaan }\end{array}$
Management. Sedangkan variabel

Tabel 3.1 Definisi Operasional dan Pengukuran Variabel

Variabel
Variabel Dependen
Pengungkapan Enterprise
Risk Management.
Pengukuran
Diukur dengan menggunakan Indeks Pengungkapan Enterprise Risk Management (ERM) dengan rumus sebagai berikut:

$$
\text { Indeks ERM }=\frac{\text { Jumlah Item yang diungkapkan }}{\text { Total item pengungkapan }}
$$

\section{Variabel Independen}

Ukuran Dewan Komisaris

Proporsi

Komisaris

Independen

Jumlah anggota dewan komisaris.

Persentase jumlah komisaris independen dari jumlah anggota dewan komisaris.

\section{Variabel Kontrol}

Ukuran Perusahaan
Logaritma natural dari total aset pada akhir tahun. 


\subsection{Metode Analisis}

Analisis data dalam penelitian ini menggunakan statistik deskriptif dan pengujian hipotesis. Pengujian dilakukan dengan menggunakan bantuan program SPSS. Sebagai persyaratan pengujian regresi berganda dilakukan uji asumsi klasik untuk memastikan bahwa data penelitian

$$
\mathrm{ERM}=\alpha_{0}+\beta_{1} \text { BOARDSIZE }+\beta_{2} \text { BOARDINDEP }+\beta_{3} \text { FIRMSIZE }+\varepsilon
$$

dimana.

$\begin{array}{ll}\text { ERM } & \text { : Pengungkapan Enterprise Risk Management, } \\ \text { BOARDSIZE } & \text { : Ukuran Dewan Komisaris, } \\ \text { BOARDINDEP } & \text { : Proporsi Komisaris Independen, } \\ \text { FIRMSIZE } & \text { : Ukuran Perusahaan, } \\ \alpha 0 & : \text { Konstanta, } \\ \beta 1 \ldots \beta 3 & : \text { koefisien regresi, dan } \\ \varepsilon & : \text { error term. }\end{array}$

\section{HASIL DAN PEMBAHASAN}

\subsection{Deskripsi Data}

Secara keseluruhan terdapat 117 data observasi laporan tahunan perusahaan non keuangan di Indonesia tahun 20142016. Tabel 4.1 di bawah ini valid, tidak bias, konsisten, dan penaksiran koefisien regresinya efisien (Gujarati, 2003). Uji asumsi klasik meliputi uji normalitas, uji multikolinieritas, uji autokorelasi, dan uji heteroskedastisitas. Persamaan regresi berganda untuk pengujian hipotesis dalam penelitian ini adalah: menjelaskan statistik diskriptif dari variabel penelitian. Informasi mengenai statistik deskriptif tersebut meliputi: nilai minimum, maksimum, rerata (mean) dan standar deviasi.

\section{Tabel 4.1 Statistik Deskriptif}

\begin{tabular}{lrrrr}
\hline \multicolumn{1}{c}{ Variabel } & Min & Mak & Rata rata & $\begin{array}{c}\text { Standar } \\
\text { Deviasi }\end{array}$ \\
\hline Ukuran Dewan Komisaris & 3 & 10 & 5,7 & 1,856 \\
Proporsi Komisaris Independen & 0,0000 & 0,8000 & 0,399278 & 0,14144115 \\
Ukuran Perusahaan & 109,36 & 55041,52 & 7548,7458 & 11995,03613 \\
Pengungkapan ERM & 0,7960 & 0,9810 & 0,882393 & 0,0472497 \\
\hline
\end{tabular}

Valid N (listwise)

Sumber: Data Sekunder yang diproses

Tabel 4.1 menunjukkan rerata tingkat pengungkapan Enterprise Risk Management (ERM) pada perusahaan nonkeuangan di Indonesia berada pada 
perusahaan nonkeuangan yang terdaftar di Bursa Efek Indonesia efektif menerapkan Sistem Enterprise Risk Management. Statistik deskriptif dari variabel independen penelitian pada Tabel 4.1. Rerata jumlah anggota dewan komisaris adalah 5 orang; rerata proporsi komisaris independen sebesar 40,07\%; dan rerata ukuran perusahaan( total asset) $\mathrm{Rp}$ 7,548 Trilun.

\subsection{Analisis Regresi Berganda}

Hasil uji normalitas berdasarkan grafik histogram dan normal probability plot menunjukkan bahwa data menyebar sekitar garis diagonal dan mengikuti arah garis diagonal. Sedangkan, data pada grafik histogram menunjukkan pola berdistribusi normal. Selanjutnya, uji Kolmogorov-Smirnov (K-S) menunjukkan bahwa besarnya nilai Kolmogorov-Smirnov adalah 741 dan signifikan pada 0,642. Jadi, dapat disimpulkan bahwa model regresi memenuhi asumsi normalitas data. Hasil uji multikolinearitas menunjukkan nilai tolerance masing-masing variabel independen nilai lebih besar dari $10 \%$ (nilai Tolerance > 0,1). Sedangkan, nilai VIF masing-masing variabel independen memiliki nilai lebih kecil dari $10 \quad(\mathrm{VIF}<10)$. Jadi, dapat disimpulkan bahwa tidak terjadi multikolinearitas pada masing-masing variabel. Uji heteroskedastisitas dilakukan dengan menggunakan analisis grafik scatter plot antara nilai prediksi variabel dependen ZPRED dengan residualnya SRESID. Dari grafik scatter plot terlihat bahwa titiktitik menyebar secara acak diatas maupun dibawah angka 0 pada sumbu $\mathrm{Y}$ artinya tidak terjadi heteroskedastisitas. Demikian pula pengujian autokorelasi yang menghasilkan nilai Durbin Watson berada pada daerah tidak ada autokorelasi.

Tabel 4.2 Hasil Regresi Berganda

\begin{tabular}{lclc}
\hline \multicolumn{1}{c}{ Variabel } & Koefisien & \multicolumn{1}{c}{$\mathrm{t}$} & $\mathrm{p}$-value \\
\hline (Constant) & 0,495 & 5,557 & 0,000 \\
Ukuran Dewan Komisaris & 0,006 & $2,279 * *$ & 0,025 \\
Proporsi Komisaris Independen6,330E-5 & 0,002 & 0,998 \\
Ukuran Perusahaan & 0,012 & $3,630 * *$ & 0,000 \\
R-Square & 0,344 & & \\
Adjusted R-Square & 0,327 & & \\
F & 19,774 & & \\
Sig & 0,000 & & \\
& & & \\
\hline
\end{tabular}

Notes: Significance at: $* 0,10, * * 0,05$, and $* * * 0,01$ levels. 
Berdasarkan hasil regresi berganda pada Tabel 4.2 diperoleh persamaan regresi: $\quad \mathrm{Y}=0,495+0,006$ BOARDSIZE $6,330 \mathrm{E}-5$ BOARDINDEP + 0,012 FIRMSIZE+ e. Berdasarkan persamaan di atas dapat ketahui bahwa variabel yang berpengaruh signifikan terhadap tingkat pengungkapan risiko perusahaan adalah Ukuran Dewan Komisaris dan Ukuran Perusahaan pada tingkat signifikansi 0,05 dan 0,01 sedangkan untuk variabel Proporsi Komisaris Independen tidak berpengaruh terhadap pengungkapan ERM.

\section{Pengaruh Ukuran Dewan Komisaris terhadap Pengungkapan ERM.}

Ukuran Dewan Komisaris ( $\rho$-value $0,025<0,050$ dan koefisien positif 0,006) menunjukkan bahwa ukuran dewan komisaris berpengaruh signifikan positif terhadap pengungkapan Enterprise Risk Management. Koefisien positif yang dimiliki ukuran dewan komisaris menunjukkan pengaruh positif ukuran dewan komisaris terhadap pengungkapan Enterprise Risk Management. Berarti hipotesis 1 diterima. Hasil ini menunjukkan bahwa semakin banyak jumlah komisaris, maka tingkat pengawasan dan tekanan terhadap manajemen semakin baik sehingga mendorong manajemen lebih transparan dalam mengungkapkan Enterprise Risk Management. Hasil penelitian ini sesuai dengan hasil penelitian Sing et. al (2004),
Abeysekera (2008), Elzahar dan Hussainey (2012).

Pengaruh Proporsi Komisaris Independen terhadap Pengungkapan ERM.

Proporsi komisaris independen $(\rho-$ value $0,998>0,050)$ menunjukkan bahwa proporsi komisaris independen tidak berpengaruh signifikan terhadap pengungkapan Enterprise Risk Management berarti hipotesis 2 ditolak. Hal ini mengindikasikan bahwa komisaris belum memahami/melaksanakan tugasnya selaku pihak independen dalam mengawasi, mengarahkan dan mengevaluasi pelaksanaan corporate governance dan kebijakan strategis perusahaan sehingga peran komisaris independen pada perusahaan nonkeuangan di Indonesia belum berfungsi sebagaimana mestinya. Hasil penelitian ini sesuai dengan hasil penelitian Ho dan wong (2001); Haniffa dan Cooke: dan Vandemele et al. (2009).

\section{Pengaruh Variabel Kontrol.}

Dalam penelitian ini terdapat variabel kontrol yaitu ukuran perusahaan. Ukuran perusahaan (pvalue $0,000>0,050$ dan koefisien positif 0,012) mencerminkan bahwa ukuran perusahaan berpengaruh signifikan terhadap pengungkapan Enterprise Risk Management (ERM) dan koefisien positif menunjukkan bahwa ukuran perusahaan berpengaruh signifikan positif terhadap pengungkapan Enterprise Risk 
Management. Hasil ini mengindikasikan bahwa perusahaan yang besar memiliki kemampuan yang lebih besar untuk menerapkan Enterprise Risk Management karena sumber dayanya yang besar.

\section{KESIMPULAN,}

\section{KETERBATASAN, DAN SARAN}

Dari hasil penelitian yang diperoleh, maka dapat diambil kesimpulan bahwa ukuran dewan komisaris berpengaruh positif terhadap pengungkapan enterprise risk management. Hasil ini menunjukkan bahwa semakin banyak jumlah komisaris, maka tingkat pengawasan dan tekanan terhadap manajemen semakin baik sehingga mendorong manajemen lebih transparan dalam mengungkapkan Enterprise Risk

Management.

Proporsi komisaris independen tidak berpengaruh terhadap pengungkapan Enterprise Risk Management. Hal tersebut mengindikasikan bahwa komisaris belum memahami/melaksanakan tugasnya selaku pihak independen dalam mengawasi, mengarahkan dan mengevaluasi pelaksanaan corporate governance dan kebijakan strategis perusahaan sehingga peran komisaris independen pada perusahaan nonkeuangan di Indonesia belum berfungsi sebagaimana mestinya

Variabel kontrol ukuran perusahaan berpengaruh terhadap pengungkapan risiko perusahaan di Indonesia. Hasil ini mengindikasikan bahwa perusahaan yang besar memiliki kemampuan yang lebih besar untuk menerapkan pengungkapan risiko perusahaan karena sumber dayanya yang besar.

Keterbatasan dalam penelitian ini adalah pada saat melakukan tabulasi data dari hasil pengamatan laporan tahunan pada perusahaan yang terdaftar di Bursa Efek Indonesia, banyak perusahaan yang menyajikan pengungkapan enterprise risk management secara tidak lengkap.

\section{DAFTAR PUSTAKA}

Abeysekera, I. 2008. The role of corporate governance in intellectual capital disclosure of kenyan listed firms. http://ssrn.com.

Abraham, S. and P. Cox. 2007. Analysing the determinants of narrative risk information in UK FTSE 100 annual reports, The British Accounting Review. 39 (3): 227-248.

Amran, A., A.M.R. Bin, and B.C.H.M. Hassan. 2009. An exploratory study on risk disclosure in Malaysian annual reports. Managerial Auditing Journal 24 (1): 39-57.

Beasley, M. 1996. An empirical analysis of the relation between the board of director composition and financial statement fraud, The Accounting Review. 71: 443-465.

Beretta, S., and S. Bozzolan. 2004. A framework for the analysis of firm risk communication, The International Journal of Accounting. 39 (3): 265-288.

Cabedo, J. and J. Tirado. 2004. The disclosure of risk in financial statements, Accounting Forum. 28 (2): 181-200.

Cheng, E. C. M., dan S. M. Courtenay. 2006. Boards composition, 
regulatory regime and voluntary disclosure. The International Journal of Accounting 41: 262-289.

Choi Frederick DS dan G. K. Meek. 2011. International Accounting. Ed.VII, New Jersey: Prentice Hall

Chorafas, D.N. 1990. Risk Management in Financial Institution, London: Butterworths.

Committee of Sponsoring Organizations of the Treadway Commission (COSO). 2004. Enterprise Risk Management - Integrated Framework, (September). New York.

Dalton, D.R., C.M. Daily, J.I. Johnson, dan A.E. Ellstrand. 1999. Number of directors and financial performance: A meta-analysis. Academy of Management Journal. 42( 6): 974686.

Dechow, R; G. Sloan dan A.P. Sweeney. 1995. Detecting Earnings Management, The Accounting Review. 70 (2): 193-225.

Dobler, M. 2005. National and international developments in risk reporting - May the German Accounting Standard 5 lead the way internationally? German Law Journal 6 (8): 1191-1200.

Dobler, M. 2008. Incentives for risk reporting: a discretionary disclosure and cheap talk approach, The International Journal of Accounting. 43 (1): 184-206.

Elzahar, H., and K. Hussainey. 2012.

Determinants of narrative risk disclosures in UK interim reports, Journal of Risk Finance. 13 (2): 13147.

Fama, E. and M. Jensen. 1983. Separation of ownership and control, Journal of Law \& Economics. 26 (4): 9-15.

Forker, J.J. 1992. Corporate governance and disclosure quality. Accounting and Business Research 22 (86): 111124.
Gujarati, D. N., 2006. Basic Econometrics $\quad\left(4^{\text {th }} \quad\right.$ edition). Singapore: McGraHill.

Haniffa, R.M., dan T.E. Cooke. 2002. Culture, corporate governance and disclosure in Malaysian corporation. ABACUS 38 (3): 317-349.

Ho, S.S.M., dan K.S. Wong. 2001. A Study of relationship between corporate governance structure and extent of voluntary disclosure. Journal of International Accounting Auditing and Taxation 10: 139-156.

Institute of Chartered Accountants in England and Wales. 1997. Financial Reporting of Risk: Proposals for a Statement of Business Risk. London: ICAEW.

Jensen M. and W. Meckling. 1976. Theory of the firm: managerial behaviour, agency costs and ownership structure, Journal of Financial Economics. 3: 305-360.

Lajili, K. and D. Zéghal. 2005. A content analysis of risk management disclosures in Canadian annual reports, Canadian Journal of Administrative Sciences. 11 (2): 125-142.

Linsley, P. and P. Shrives. 2005. Examining risk reporting in UK public companies, Journal of Risk Finance. 6 (4): 292-305.

Linsley, P. and P. Shrives. 2006. Risk reporting: a study of risk disclosures in the annual reports of UK companies, The British Accounting Review. 38 (1): 387-404.

Lukviarman, N. 2004a. Etika bisnis tak berjalan di Indonesia: Ada apa dalam corporate governance. Jurnal Siasat Bisnis 9 (2): 139-156.

Lukviarman, N. 2007. Board governance menuju penguatan corporate governance di Indonesia. Pidato pengukuhan sebagai guru besar tetap dalam bidang corporate governance, pada Fakultas Ekonomi 
Universitas Andalas, padang 7 Juni 2007.

McGee, R. W. 2009. Corporate Governance in Developing Economic. Florida International University 3000 NE., 151st Street North Miami FL 33181 USA; Springer Science Business Media, LLC

Meizaroh dan Lucyanda. 2011. Pengaruh corporate governance dan konsentrasi kepemilkan pada pengungkapan enterprise risk management. Simposium Nasional Akuntansi XIV Aceh: Universitas Bakrie Jakarta, Page 1-30.

Monks, A. G. dan N. Monow. 1995. Corporate Governance. Balkwell Business, Cambridge, Mass. 8- 32.

Morris, R. 1987. Signaling, agency theory and accounting policy choice, Accounting and Business Research. 18 (69): 47-56.

Singh, M; I. Mathur, and K. Gleason. 2004. Governance and performance implications of diversification strategies: evidence from large US firms, Financial Review. 39: 489526.

Solomon, J; A. Solomon, S. Norton, and N. Josef. 2000. A conceptual framework for corporate risk disclosure emerging from the agenda for corporate governance reforms, British Accounting Review. 32 (4): 447-478.

Shleifer, A., and R. Vishny. 1997. A survey of corporate governance. Journal of Finance 52 (4): 737-775.

Tunggal, A.W. 2009. Pokok-Pokok Manajemen Risiko. Jakarta: Harvarindo.

Vandemele, S., P. Vergauwen, and A. Michiels. 2009. Management risk reporting practices and their determinants: A study of Belgian listed firm. Available at:https://uhdspace.uhasselt.be/dspac e/bitstream/1942/9392/2/Corporateris kB.pdf 